\title{
Capturing Violence in the Night-Time Economy: A Review of Established and Emerging Methodologies
}

\author{
Richard PHILPOT 12 \\ (ORCID 0000-0002-0359-2123) \\ Lasse Suonperä LIEBST ${ }^{2}$ \\ (ORCID 0000-0003-1062-2447) \\ Kim Kristian MØLLER ${ }^{3}$ \\ (ORCID 0000-0002-4417-1253) \\ Marie Rosenkrantz LINDEGAARD ${ }^{24}$ \\ (ORCID 0000-0002-1630-774X) \\ Mark LEVINE 15 \\ (ORCID 0000-0001-5696-6021)
}

${ }^{1}$ Department of Psychology, Fylde College, Lancaster University, Lancaster, LA1 4YF, United Kingdom

${ }^{2}$ Department of Sociology, University of Copenhagen, Øster Farimagsgade 5A, Bld. 16, Copenhagen K, Denmark

${ }^{3}$ Department of Criminology, Malmö University, 20506 Malmö, Sweden

${ }^{4}$ Netherlands Institute for the Study of Crime and Law Enforcement (NSCR), P.O. Box 71304, 1008 BH Amsterdam, The Netherlands

${ }^{5}$ Department of Psychology, University of Exeter, Perry Road, Exeter, EX4 4QG, United Kingdom

Acknowledgement: This work was supported by the Engineering and Physical Sciences Research Council [EPSRC - 1402902] and the Danish Council for Independent Research [DFF - 6109-00210]. The funders had no role in the design of the paper, analysis, decision to publish, or preparation of the manuscript.

\footnotetext{
*Corresponding author, e-mail r.philpot@lancaster.ac.uk
} 


\begin{abstract}
Night-time economy (NTE) leisure zones, while providing local economic growth and positive social experiences, are hotspots for urban public violence. Research aimed at better understanding and thus reducing this violence has employed a range of empirical methods: official records, self-reports, experiments, and observational techniques. In this paper, we review the applications of these methodologies for analyzing NTE violence on key research dimensions, including mapping incidents across time and space; interpreting the motivations and meaning of violence; identifying social psychological background variables and health consequences; and the ability to examine mid-violent interactions. Further, we assess each method in terms of reliability, validity, and the potential for establishing causal claims. We demonstrate that there are fewer and less established methodologies available for examining the interactional dynamics of NTE violence. Using real-life NTE bystander intervention as a case example, we argue that video-based behavioral analysis is a promising method to address this gap. Given the infancy and relative lack of exposure of the video observational method, we provide recommendations for scholars interested in adopting this technique.
\end{abstract}




\section{Introduction}

The rise of the night-time economy (NTE)—characterized by leisure zones, cheap alcohol deals, and extended drinking hours - has created urban spatial hot spots of reported violence and anti-social behavior (Allen, Nicholas, Salisbury, \& Wood, 2003; Hadfield, Lister, \& Traynor, 2009). Highlighting the prevalence of NTE violence, surveys conducted in Australian and British cities show that between half to three-quarters of NTE patrons have witnessed violent encounters, with 10-17 percent having a direct involvement in the violence (Miller et al., 2012, 2016a; Porter, 2015). These dramatic figures are depicted as a crisis for state policing, that has led to greater public anxiety and to new political reforms (Hobbs, Hadfield, Lister, \& Winlow, 2005; Lister, 2009; Measham \& Brain, 2005).

Such adverse social developments have directed scholarly interest towards the factors that may explain this concentration of violence. For example, a large body of work has established a positive relationship between alcohol consumption and aggression in the laboratory (Bushman \& Cooper, 1990; Ito, Miller, \& Pollock, 1996) and NTE settings (Wilkinson, Livingston, \& Room, 2016). While alcohol is disproportionately prevalent in cases of interpersonal violence, the vast majority of intoxicated individuals do not behave violently (Collins, 2008; Giancola, 2013). Further, the influence of alcohol on aggression is moderated by individual risk factors, including dispositional traits, affect, and beliefs on violence (Barnwell, Borders, \& Earleywine, 2006; Finkel \& Eckhardt, 2013; Giancola, 2004, 2013; Leonard \& Senchak, 1993). Researchers also examine how the dense concentration of individuals and the competition for resources (e.g., taxis and food) may create 'frictional' conditions favorable for violent encounters (Macintyre \& Homel, 1997; Townsley \& Grimshaw, 2013; but see Block \& Block, 1995). Social crowding may also facilitate anonymity and a lack of accountability that reduces moral responsibility and increases the likelihood of anti-social behavior (Latané \& Darley, 1970; Milgram, 1970, but see Postmes \& 
Spears, 1998). Finally, a line of research highlights barroom cultures that endorse recreational fighting and the use of violence to settle disputes (Copes, Hochstetler, \& Forsyth, 2013; Levine et al., 2012).

It is beyond the scope of this paper to assess the relative empirical contributions of each research strand to explain NTE violence. Rather, the aim of the current article is to review the strengths and limitations of the methodological approaches chiefly applied in studies of NTE violence. Specifically, the current paper outlines four main methods employed to study NTE violence (official records, self-reports, experiments, and observations) while detailing their various subtypes (e.g., observations may be participatory, on-site non-participatory, or video-based non-participatory). In doing so, we critically evaluate each methodological subtype with supporting illustrative examples from prior NTE research.

Next, as a summary of this review, we outline a matrix that plots the different methods against epistemological research dimensions (e.g., the capacity to establish causal claims, or the ability to interpret the subjective meaning of violence) allowing researchers to consider methodological triangulation. We use this matrix to argue that methods for studying violence in-situ are less well developed or adopted by researchers. To address this gap, we advocate the wider use of video observational techniques to study violent NTE interactions as they occur in their 'here-and-now' contexts (Farrington, 1998; Levine, Taylor, \& Best, 2011). This methodological prospect is summarized by Collins (2008): "the video revolution has made available much more information about what happens in violent situations than ever before" (p.5). For scholars interested in adding video behavioral analysis to their methodological toolbox, however, there is a notable dearth of guidelines available to understand the prospects and pitfalls of this emerging approach (Lindegaard \& Bernasco, 
2018; Nassauer \& Legewie, 2018). We therefore conclude with a discussion of the prospects of NTE video research—drawing out some guiding principles for the research community.

\section{Review of methodological approaches to study NTE violence}

We searched on the terms 'night time economy,' 'violence,' and their equivalents (e.g., 'barroom,' 'aggression') in combination with method terms (e.g., 'interview,' 'survey,' 'observation') as generally applied across the scholarly fields examining NTE violence (see e.g., Bickman \& Rog, 2008; Elmes, Kantowitz \& Roediger III, 2011; Maxfield \& Babbier, 2014). Given the interdisciplinary and extensive nature of the NTE violence field, we used Google Scholar, which is known to provide the most comprehensive coverage of the research literature with the least publisher bias (MartínMartín, Orduna-Malea \& López-Cózar, 2018; Wohlin, 2014). We supplemented this database search with snowballing, whereby we examined the reference lists of papers to identify additional work (Wohlin, 2014). The studies we identified in this search were discussed among the research team. We selected studies to include in this article based on an assessment of their contribution to the method discussion, that is our focus. As such, we do not purport to present an exhaustive sample of research on violence in the NTE, but a sample that captures the key methodological discussions in the field.

\section{Official records}

The principle source of data regarding violence in the NTE is police-recorded crime. This data offers a wealth of information on levels of violence, changes over time, and the geographical hot spots in which harm is most prevalent (Burrell \& Erol, 2009; Hadfield et al., 2009). Official records may contain information on socio-psychological and demographic background variables related to offenders and victims, and can be very rich in detail (Hedlund, Ahlner, Kristiansson, \& Sturup, 2014). 
Studies applying police-recorded data consistently identify the pattern that crime is highly concentrated in a small number of places (Lee, Eck, O, \& Martinez, 2017). This 'law of crime concentration at place' (Weisburd, 2015) is also applicable to NTE violence research. Illustrating this trend, several studies document a spatial correlation between alcohol licensed premises and registered violent crime (Gmel, Holmes, \& Studer, 2016; Gorman, Speer, Gruenewald, \& Labouvie, 2001). UK survey statistics show that approximately one-in-five violent incidents occur in, or directly around, drinking premises (Porter, 2015), while the Danish victimization survey finds that 10-15 percent of all violence takes place at NTE establishments (Pedersen, Kyvsgaard, \& Balvig, 2017).

Official records also detail the temporal dimension of crime. Newton (2015) examined the daily and hourly fluctuations of NTE reported violence and found that assaults were most prevalent in the early hours of the morning, Friday through to Sunday. NTE violence is also found to fluctuate over the calendar year, with higher peaks around many national holidays, annual celebrations, and noteworthy sporting events (Bellis et al., 2012). Additionally, studies show that restrictions in the opening hours of alcohol premises is associated with a decrease in police reported violence (Sanchez-Ramirez \& Voaklander, 2018; Wilkinson, Livingston \& Room, 2016; but see Humphreys, Eisner, 2014).

Applications of official records has been very successful in mapping out the 'where' of public violence concentration, as well as the temporal fluctuations of 'when' violence is likely to occur. This information is instrumental in the development of evidencebased crime prevention strategies; in particular, hot spot policing practices (Braga, Papachristos, \& Hureau, 2014; Braga \& Weisburd, 2010; Sherman \& Weisburd, 1995). One limitation of official records, however, is that by providing broader descriptions, these statistics are less useful (Gmel et al., 2016), or utilized (Groff, Weisburd, \& Yang, 2010; 
Weisburd, 2015), for explaining 'why' particular times or places become hot spots for violence.

Official records suffer further from a selection bias, because only the incidents witnessed on police patrols, or directly reported to the authorities, are recorded (Schwartz \& Vega, 2017). In the NTE context, Brennan (2011) notes that some drinkers are reluctant to report violence when socializing and intoxicated, leading to fewer reported incidents. Similarly, victimization surveys consistently show that a significant proportion of victims do not report their assault to the police (Kershaw, Nicholas, \& Walker, 2008; Pedersen, Kyvsgaard, \& Balvig, 2017). Police may also choose not to report the assaults they attendparticularly if low in severity — or administer fines, where jurisdictions allow, as an alternative to official reporting (Methven, 2014; Schwartz \& Vega, 2017). The above examples are reflected in the finding that only one quarter to one third of violent incidents that appear in hospital Accident and Emergency datasets also appear in police records (Florence, Shepherd, Brennan, \& Simon, 2011). Wide discrepancies are also noted between police records and ambulance service data, leading scholars to question the reliability of police data for analyzing the nature and extent of alcohol-related violence (de Andrade, Homel \& Townsley, 2016; Kypri, 2015; Shepard, 2007). Finally, official records do not provide detail on the individuals' own perceptions of the violent incidents they experience, or of how people actually behave as the aggressive episode unfolds. This makes it difficult to assess the social mechanisms by which turning points occur, towards or away from violence.

\section{Self-reports: surveys and interviews}

Self-reported accounts of NTE violence complement official statistics by offering greater description of the real experiences and behaviors enacted during aggressive episodes. The two key sources of self-reports are quantitative surveys (e.g., victimization surveys, venue questionnaires, offsite questionnaires) and qualitative interviews. 
National wide victimization surveys are administered in large quantities with the aim of providing a population representative picture of the proportion of violent victimizations that occur in the NTE. What is more, victimization surveys also provide information on the victims' pre- and post-experiences, and some behavioral properties of the mid-violent event (van Kesteren, van Dijk, \& Mayhew, 2014). Victimized individuals may be asked the assumed motivational cause of the violent attack (revenge, unprovoked, etc.), specifically how they were victimized (e.g., weapon use, from strangers or familiars), and whether they had received support from relevant agencies in the aftermath of the event (Pedersen et al., 2017; van Kesteren et al., 2014).

As an alternative to random-population sampling, researchers also apply purposive sampling to study the subgroup of individuals who frequent the NTE. These surveys can be conducted by researchers present in the NTE setting (i.e., on the street, in nightclub queues, in venues —e.g., Hughes, Anderson, Morleo \& Bellis, 2008; Miller et al., 2016a), completed offsite (through online, postal, or telephone questionnaires-e.g., Miller et al., 2016b; Schnitzer et al., 2010), or a combination of both (see Street Intercept Method; Graham et al., 2014). This allows researchers to assess a range of detailed personal and situational risk factors associated with violence. For example, a European wide, crosssectional respondent-driven survey asked 1,341 young individuals about their experiences of NTE violence, combined with measures of age, gender, drug and alcohol consumption, and venue setting (Schnitzer et al., 2010). Results showed that for both males and females the likelihood of being involved in a NTE fight increased with lower age, higher levels of intoxication, and with preferences for attending venues more tolerant towards deviant behaviors. Surveys have also been used to examine patron perceptions of safety in NTE zones (Miller et al., 2012), levels of aggressive involvement and experiences of harm (Miller et al., 2016a), as well as the consequences of working in 'at risk' NTE occupations. Tutenges 
and colleagues (2015) surveyed 159 bouncers and found that the majority reported having been physically assaulted in their occupational role and having suffered from weekly sleeping difficulties.

As quantitative surveys typically apply a closed-ended format, however, they are limited in the amount of specific detail they can acquire from participants. Qualitative interviews, by comparison, tend to be conducted in a more open-ended, typically semistructured manner, that allows finer-grained explorative accounts of experiences (Lindegaard, Bernasco, \& Jacques, 2015; Wellington \& Szczerbinski, 2007). Qualitative interviews may be obtained from secondary sources, e.g., victim and offender statements in police case files (Liebst, Heinskou, \& Ejbye-Ernst, 2018; Weenink, 2014), but are mainly conducted by the academic scholars themselves. Such interviews have been utilized to examine the conflict experiences of all social roles in the NTE, including perpetrators (Graham \& Wells, 2003; Hochstetler, Copes, \& Forsyth, 2014), victims (Nicholls, 2017), bystanders (Levine et al., 2012), NTE staff (Hobbs, O'Brien, \& Westmarland, 2007), and key NTE informants (e.g, the police, liquor licensees, council workers; Miller et al., 2012). For example, Copes, Hochstetler and Forsyth (2013) interviewed 23 males who had been in several bar fights and identified common motivations for conflict (e.g., verifying one's masculine self-image and maintaining hierarchies) and normative rules of conduct (e.g., fight others of similar physical size, with equal numbers on both sides). Miller and colleagues (2012) conducted 97 in-depth interviews with key NTE informants of two regional Australian cities and found large variation in the respondents' perceptions of NTE violence trends. Specifically, while some respondents emphasized an increased normalization of severe NTE violence, others perceived violence levels as stable, or as falling in parallel with a declining number of NTE visitors.

Although self-reports provide detailed description on the experiences and behaviors of NTE persons, the limitations of such method are well known, and may be 
accentuated by circumstances of the NTE setting. Participant response bias implies that more socially desirable answers are expressed and negative behaviors are understated. This is especially pertinent for sensitive and socially disapproved topics including aggression and violence (Gregoski, Malone, \& Richardson, 2005; Saunders, 1991; Sykes \& Matza, 1957). Furthermore, retrospective accounts of violent episodes may be inaccurate owing to cognitive constraints, false memories, self-deception, and memory failure - phenomena found to increase in times of high stress or aggression (Laney \& Takarangi, 2013; Saunders, 1991; Vrij, Hope, \& Fisher, 2014). Adding to this issue, because violence in the NTE often serves as a symbolic means of status and masculinity validation, patrons may provide dramatized narratives and distorted self-presentational accounts of actual events (Collins, 2008;

Hochstetler et al., 2014; Jackson-Jacobs, 2004).

\section{Experiments: laboratory and field interventions}

To circumvent reliability issues of other data sources (e.g., self-reported accounts) and to identify the causal factors influencing violence in all contexts (NTE included), scholars have advocated the study of aggression in controlled laboratory settings (Anderson \& Bushman, 1997; Levine, 2003). These laboratory studies typically provoke a participant under varying conditions and measure the subsequent aggressive behavioral reaction. Once provoked, these experiments allow the participant to administer an unpleasant response to a potential victim—-such as a mild shock or noise blast, a dose of hot sauce, a written insult, or to place virtual pins in a voodoo doll (for examples, see Finkel, 2014).

Laboratory experiments have identified a range of interacting risk factors for aggression — both personal (e.g., gender, attitudes, personality traits) and situational (e.g., pain, heat, alcohol) (for reviews see Anderson \& Bushman, 2002; Finkel, 2014; Giancola, 2013; Taylor \& Leonard, 1983). However, although ethical restrictions make it difficult to measure direct physical harm, it remains debatable whether these novel outcome 
measurements are in fact aggressive, amusing, or perhaps even inadvertently cued by the experimenter (Ritter \& Eslea, 2005). While the experimental method is the gold standard for establishing causation, the trade-off is that by decontextualizing violence in favor of controlled settings, there is a reduction in "the complexity, diversity, and contextual aspects of real-world aggression" (Graham et al., 2006, p. 21). These simulations are also artificial insofar as they are unlikely to produce the same high tension and adrenaline experienced under real-life violent threats.

To enhance the ecological validity of laboratory studies, researchers have recently advocated the use of virtual reality technologies (van Gelder, Otte, \& Luciano, 2014). For example, in a recent study, Slater et al. (2013) simulated an immersive barroom fight and found evidence that social group membership may increase the likelihood of bystander intervention. Although virtual reality allows a new way to contextualize violence in a controlled setting, it remains unclear the extent to which this technological advancement satisfies the wider call for improved ecological validity in experimental research, and particularly, the recommendation that this can be best achieved by field experimental methods (Baumeister, Vohs, \& Funder, 2007; Cialdini, 2009).

Besides the laboratory experiments, field experimental interventions have been widely applied to evaluate crime prevention initiatives in NTE settings. One line of research examines, through natural experiments, whether policy driven restrictions in alcohol trading hours are effective in reducing levels of NTE violence (Humphrey \& Eisner, 2014; Rossow \& Norström, 2012). In addition to naturally occurring interventions, researchers have also applied randomized controlled trials to examine how changes in closing-hours (Kypri, McElduff, \& Miller, 2014; Kypri, Jones, McElduff \& Baker, 2011), targeted policing (Gerell, 2016), and bar practice interventions (Graham et al., 2004; Moore et al., 2017) affect rates of NTE violence. For example, controlled trials of hot spot policing conclude that police 
presence is effective at reducing numerous forms of crime and delinquency (Braga et al., 2014). However, recent intervention studies question how effective police presence is at reducing violence in NTE settings. Specifically, Gerell (2016) found no change in the number of violent assaults in NTE areas in which an intervention combined hot spot policing with actively monitored CCTV. Similarly, the deployment of private security guards to monitor problematic NTE streets in Sweden was not associated with a significant reduction in violent street assaults (Frogner, Andershed, Lindberg, \& Johansson, 2013).

A number of randomized controlled trials also target NTE bar practices. Graham et al. (2004) and Moore et al. (2014) provide evidence that practitioner audits and staff training can be effective in reducing violence in a large number of alcohol premises. Most recently, however, an extensive randomized trial involving 600 alcohol premises found that practitioner audit intervention and training led to an increase in violent incidences (Moore et al., 2017). This unexpected result highlights the practical difficulties of delivering sustainable, externally led, NTE interventions and emphasizes Kypri's (2017) call for more ecologically valid evaluations of alcohol related violence.

\section{Observations: on-site non-participatory and participatory approaches}

In order to investigate naturally occurring behavior of individuals during NTE mid-violent events, and to partially address the ecological validity concerns of experimental studies and the reliability issues of self-reported studies, some scholars have advocated for naturalistic observations of NTE violence (Graham et al., 2006; Levine et al., 2011; Liebst, Heinskou, et al., 2018; Philpot, 2017).

On-site non-participatory observations deploy an uninvolved observer to systematically record the actions of individuals and the situational properties of an unfolding violent event. This method has identified relationships between environmental features-such as spatial design, cleanliness, and people density—and aggressive outcomes (Graham \& 
Homel, 2012; Macintyre \& Homel, 1997; Townsley \& Grimshaw, 2013). Further, scholars have applied on-site observations to examine bar management styles and serving practices as predictors of barroom violence (Graham et al., 2004; Homel \& Clark, 1994). This research has also demonstrated how social features such as masculinity and gender explain differences in displays of aggression (Forsyth \& Lennox, 2010; Kavanaugh, 2015, but see Wells, Speechley, Koval \& Graham, 2007). Finally, research using on-site observations has provided insights into the situational features (e.g., the severity of aggression) that lead bystanders to intervene in barroom aggression (Parks, Osgood, Felson, Wells, \& Graham, 2013).

Despite the empirical advances owing to this method, on-site non-participatory observations are limited through their dependence on the sightings of single, or sometimes pairs of, on-site coders. Human coders are never a tabula rasa, but instead enter any observational setting with stereotypes, biases, and beliefs (Caldwell \& Atwal, 2005; EiblEibesfeldt, 1989). This may result in confirmation bias, as coders unconsciously look for, and interpret, information that is consistent with their research question, and discard or ignore real-time evidence that does not fit with an alternate hypothesis.

Furthermore, the coders, while trying to remain obscure, cannot observe from a bubble; rather they are intermingled in the immediate situation around them. One benefit of this is that it allows a better feel for the violent situation unfolding around (e.g., the sounds, smells, and emotional tensions). However, the presence of an observer may disturb the natural behaviors of those the observer intends to code (LeCompte \& Goetz, 1982). To remain as inconspicuous as possible, coders may opt to abstain from making detailed notes until after their observation has finished (e.g., Parks et al., 2013). This delay, however, exposes observations to the same false memories, unconscious self-deceptions, and recollection failures usually attributed to the self-report methods. As such, a preferred 
approach is to capture data immediately in the situation itself using mobile devices, which are commonplace within public settings and thus effectively unobtrusive (Coomber et al., 2016; Miller et al., 2013).

Owing to the complexity and chaotic nature of violent episodes, and the large number of people simultaneously contributing to the outcome, it is often impossible for an on-site observer to account for (particularly chronologically, detailed, or second-by-second) all behaviors pertained across all actors (Morrison, Lee, Gruenewald, \& Mair, 2016; Simons \& Chabris, 1999). The deployment of multiple on-site coders does not fully account for these concerns, or ensure entirely reliable observations (Adang, 2016), meaning that detail of what is occurring between those in, and around, the situation may be lost. Highlighting these concerns, a recent study assessing the reliability of on-site observations in bar settings concludes that "as a general rule, it appears that while both the fixed characteristics of these outlets and public activities of social groups in these outlets can be readily observed and reliably assessed, individual characteristics and specific social interactions cannot" (Morrison et al., 2016, p. 335).

In contrast to the non-participatory approach, a researcher conducting participatory observations partakes in the activities of the individuals under study. This participation allows the scholar to experience, understand, and thus eventually explain, the social meaning of the practices from an insider perspective (Geertz, 1973; Jorgensen, 1989). As an illustration, a bystander who intervenes into a conflict in a violent manner may be perceived, in the eyes of an outsider, as an escalatory individual. However, for the participatory observer familiar with the participants and their practices, this forceful intervention may, in fact, communicate de-escalation, by which the bystander uses violence for the overall sake of non-violence (see Stott, Hutchison, \& Drury, 2001). 
More broadly, participant observations are typically carried out in order to observe practices that are difficult to access through retrospective accounts, because they are embodied as ordinary and habituated routines that the participants are unaware of (Bourdieu, 1999). In an ethnographic study of Canadian bar room fights, Dyck (1980) found that young men were expected to get involved in fights when their reputation was challenged by peers. These fights were short encounters that were not considered violence, but ordinary forms of interactions within bar room culture, and were thus not reported to the police.

While a large body of ethnographic work examines the social meaning of bar room fights between ordinary patrons (Benson \& Archer, 2002; Perez-Trujillo, Reyes, Cabrera, \& Gomez, 2016; Tomsen, 1997), as well as within subcultures who frequent the NTE (e.g., English football firms, see Ayres \& Treadwell, 2012), this approach has also been employed to study occupational cultures. For example, Winlow and colleagues (2001) immersed into the barroom culture by working as a bouncer. They found that a bouncer's expertise in recognizing the trajectory of a conflict was invaluable in preventing violence escalation. Also immersing himself as a bouncer, Monaghan (2002) identified how building up body size and fighting skills prepare bouncers symbolically and physically for occasions when their bodies may be put at risk. Interestingly, in a more recent study, Geoffrion et al. (2017) asked the security staff themselves to act as participant observers to identify the shifting hot spots of aggressive incidents within their nightclub.

An important strength of participant observation is that the observer may be considered an insider by the people under study, owing to the extensive time periods of engagement. This makes the participatory researcher less likely to influence the behavior observed in comparison to the non-participatory observer. Also the participant observer is able to record aspects of the social phenomena that other methods do not allow for, such as the feeling of being in a fight. A key weakness is that participant observers are likely to be 
biased in their focus and often unable to systematically analyze the behavior observed because of their own involvement (Hammersley \& Atkinson, 1995).

\section{Video observational analysis}

A way to circumvent the over-reliance on in-situ coders, and yet retain the numerous benefits of direct observation, is to assess the natural behaviors captured on prerecorded videos (Collins, 2008; Farrington, 1998; Lindegaard \& Bernasco, 2018; Nassauer \& Legewie, 2018). A camera can indiscriminately record all unobscured actions within its field of view, without fatigue or lapses in concentration. Video data can be replayed, rewound, paused, and slowed down to frame-by-frame instances. This provides a second-by-second account of the events that unfold and allows iterative identification and inclusion of behaviors missed if only viewed once, as is the case for on-site observation. Thus, video observational analysis allows the researcher to exploit the chronological chain and temporal properties of the interaction sequence (Collins, 2008; Levine et al., 2011; Nassauer \& Legewie, 2018). Adding to this, video data allows checks in inter-rater reliability between coders and the verification of existing coding frameworks, enabling a rigorous and highly-detailed, behavioral analysis - a necessity long advocated in the observational tradition (Johnson \& Sackett, 1998; Reiss, 1991).

There has been an exponential rise in CCTV surveillance over the past decades. For example, conservative estimates from the UK approximate at least 1.85 million CCTV cameras across Britain; 1 in operation for every 34 persons (Gerrard \& Thompson, 2011). While this increased camera presence has assisted to identify and prosecute violent offenders, and helped reduce some premeditated crimes (e.g., property crime, shoplifting), the metaanalytic evidence suggests that CCTV cameras are ineffective at deterring more emotionally reactive crimes, such as violent assaults in public spaces (Alexandrie, 2017; Welsh \& Farrington, 2009). Yet, microanalyses of video-recorded violent behaviors have allowed 
researchers to establish, with the highest degree of micro-detail so far, how perpetrators, victims, and bystanders actually act during public violent events (Collins, 2008; Lindegaard \& Bernasco, 2018). In particular, this method has been used to analyze bystander interventions in NTE violence, as to address a set of essential, yet under-examined, questions - is third-party intervention common, effective, dangerous, and why do people intervene?

Levine and colleagues (2011) offered the first systematic video behavioral analysis into how third-party bystanders achieve social control during real-life NTE violence. They conducted a micro-behavioral coding of the de-escalatory and escalatory bystander actions performed across 42 British CCTV clips of NTE conflicts. Contrary to the scholarly assumption that group gatherings promote anti-social behavior because of the irrationality and anonymity they engender in individuals (e.g., Baumeister, Ainsworth, \& Vohs, 2016; Crawford \& Flint, 2009; Diener, 1976; Zimbardo, 2007), increased group size was not associated with an increase in escalatory behaviors. Rather, the analysis showed a group tendency to contribute de-escalation during NTE fights over escalation. In contrast to five decades of experimental bystander effect research, suggesting that members of public are largely apathetic during emergencies (Fischer et al., 2011; Latané \& Darley, 1970), increased bystander presence predicted a higher rate of de-escalatory intervention. An additional analysis showed that the sequential persistence of de-escalatory interventions from third-party bystanders was most important in predicting whether a conflict did not escalate to severe violence.

Further stressing the prominence of third-party bystander intervention in NTE fights, Philpot (2017) found that at least one bystander intervened across 43 separate incidents captured by CCTV. Over three quarters of all bystander actions recorded were deescalatory in nature, indicating that third-parties were active players who largely tried to 
regulate NTE fights. Examining predictors of real-life intervention, Liebst, Philpot and colleagues (2018) found that group relations - rather than group sizes as suggested by the bystander effect — was the main predictor of bystander intervention across 61 video-recorded conflicts. Assessing the risk associated with such interventions, Liebst, Heinskou and EjbyeErnst (2018) analyzed the likelihood of physical victimization for 229 intervening bystanders across 64 CCTV captured assaults. The overall likelihood of bystander victimization when intervening was fairly low, with the key risk factor being the bystander's group relationship with the defended victim.

These examples illustrate how video behavioral analyses of real-life encounters may provide new insights into how patrons of the NTE behave during violent conflicts. From systematically observing what people do during NTE violence, this line of research is well placed to challenge scholarly assumptions which are ecologically detached from how individuals are actually behaving (Altmann, 1974; Baumeister et al., 2007; Mortensen \& Cialdini, 2010). This is not only important from an academic perspective, but also for current NTE crime prevention practices. As aforementioned, the dominant scholarly view is that individuals are more likely to act anti-socially when together in masses, and this assumption aligns with the practice of authorities to disperse public space groups (Porter, 2015). As described, however, CCTV footage evidences that a notable amount of NTE violence is 'policed' by the public groups themselves (Levine et al., 2011; Liebst, Philpot, et al., 2018; Philpot, 2017). Hence, police efforts to restore public order through the dispersion of groups may have an adverse effect, if these group processes of self-policing are unnecessarily disturbed (Levine et al., 2012; Stott, Scothern, \& Gorringe, 2013).

Video-based analysis also holds the prospect of creating a new crime prevention evidence base that so far has been absent. Previously, because of the non-application of video approaches, very little was known about the actual risk posed to bystanders when intervening 
in public space conflicts (Liebst, Heinskou, et al., 2018). Given this vacuum, some crime prevention councils have been reluctant, for good reason, to provide recommendations on whether bystanders should intervene in NTE violence. However, informed from the systematic evidence of Liebst and colleagues (2018), the Danish Prevention Council has recently started to recommend that bystanders can take a de-escalatory role in NTE violence, with a limited degree of known risk (Dalgas, 2017).

Despite the scholarly and practical advantages of the video observational approach, there are number of methodological limitations important to caveat. While video data allows for a very fine-grained behavioral analysis, this can also be a hindrance in itself. Researchers may be tempted to code at a resolution level excessive for their study purposes, simply because it is possible to do so, and the available software for behavioral coding (e.g., BORIS, Observer XT) may invite such (Uprichard, Burrows, \& Byrne, 2008). This could involve coding all behavioral acts, for all individuals, across all time points of the footagebehaviors that may then be discarded or aggregated to a higher level later in the research process (Philpot, 2017; see also, Birdwhistell, 1970). As the coding of video footage is labor intensive, such 'over-coding' is costly.

Like on-site observation, researchers using CCTV footage are also restricted in what they can see (e.g., due to resolution, awkward filming angles, poor focus) and whether they have complete capture of the episode of interest (see Nassauer \& Legewie, 2018). Thus, depending on the specific video inclusion criteria, researchers may exclude between half (Liebst, Heinskou, et al., 2018) and three-quarters (Levine et al., 2011) of their sampled raw clips. Furthermore, as surveillance cameras are installed and maintained by bodies external to the researchers (e.g., a city council, police force, or proprietor), there are large variations in data accessibility and a risk that data is over-edited, incomplete, or selected on unknown, biased criteria. With regards to this latter issue (Berk, 1983), a reliance on CCTV footage 
collected from police case files may bias data towards sampling on the dependent variablei.e., cases that contain violence, most likely high in severity. Data sampling may also be biased towards areas that experience greater NTE violence issues, or conversely, towards good venues and municipalities that proactively install surveillance cameras to deter antisocial behavior. Similarly problematic, convenience sampling from social media platforms (e.g., YouTube) most likely limit data to the less mundane, extraordinary cases (Lindegaard \& Bernasco, 2018). When considering the validity of the sample, there is also the question of how reactive participants are to being surveilled (Alexandrie, 2017; van Bommel, van Prooijen, Elffers, \& van Lange, 2014; Welsh \& Farrington, 2009).

A final, yet important limitation of applying CCTV footage for research purposes is that this data source typically displays only visual information. As such, researchers have rich information on behaviors ('hand'), but no direct knowledge of the individual's feelings ('heart'), or thoughts and their verbalizations ('head') (see Phillips, 2001). CCTV footage, therefore, conveys limited insights into the social meaning of the event and the individual motivations for actions.

\section{Discussion}

NTE zones offer recreational benefits for its patrons and valuable boosts to local economies. However, they also remain hot spots for anti-social behavior and violence. In this paper, we assessed the research methods employed to understand, and in turn reduce, NTE violence. Multiple methods are available in the NTE researcher's tool-kit to study violence in public spaces. Each approach has been successfully applied in the field and has inherent qualities that have furthered our understanding of NTE violence. In the following matrix (see Table 1), we provide a brief overview of the four main methods employed to study NTE violence (official records, self-reports, experiments, and observations) and their eight subtypes. We summarize the analytical capacities of each subtype with the ambition to 
help future researchers decide which method, or methods, are suitable for their own research requirements. 
Table 1. Assessment of current methodologies to analyze NTE violence

$$
\text { Official records }
$$
Self-report

$$
\text { Official records }
$$

$$
\text { Surveys }
$$

Interviews

Ability to map incidents across time and space

Ability to establish causal claims (study control)

Medium

Ability to assess

motivation and

meanings of violence

Labor intensiveness

Validity for the assessment of violent interactions

Reliability for the assessment of violent interactions

Ability to assess socio-psychological background variables

Ability to assess socio-psycho-health consequences

Existence of established methodological guidelines

High

Medium

Low

Medium

Medium

High

Low

Low - Medium

Low

Low - Medium

Low - High

High

Low - High

High

High

High

High
Low - Medium

High

High

Low - Medium

Low

High

Low

High

High

High

Medium - High

Low

Low

High

High

High

Low - Medium

High

Low

Low - Medium

Low - Medium

High

Medium - High

High

Low

Medium - High

Low

Low
Low

Low

High 
For those interested in mapping the distribution of violent incidents across time and space, a quantitative approach relying on official records or field interventions (incorporating official records) is preferred. Street-based CCTV could also provide video observational scholars with information on the event distribution of NTE violence-although this remains to be done in practice and would require a very high degree of CCTV coverage. To examine casual mechanisms involved with violence, quantitative experiments, both laboratory and field intervention types, are the strongest approach—although the ecological validity of assessing real-life violent interactions is limited. In contrast, for researchers examining the motivations and meaning context of NTE violence, a qualitative approach that utilizes interviews or participant observational techniques is most suitable.

Several of the quantitative (e.g., surveys, laboratory experiments) and qualitative approaches (e.g., interviews, participant observation) are capable of relating sociopsychological background conditions and consequences to NTE violence. In contrast, systematic techniques of non-participant observation (both on-site and video-based), are unable to furnish such information. By focusing on the mid-event conflicts, however, nonparticipant observation offers an ecologically valid assessment of the violent interactions as they unfold in real-time, hence providing insights into the situational causes of violence. Further, it is noteworthy that non-participant on-site observation and video assessments are very similar in regards their overall methodological strengths and weaknesses, with the key exception being the reliability for the assessment of violent interactions. Here, the advantage of replaying videos allows for more rigorous checks. Therefore, if interested in behavioral interactions, video data should take priority over human on-site coders.

Finally, it is notable that the majority of methods assessed are well-established, besides the non-participatory observational approaches, which are surprisingly underutilized across the social sciences (Martin, 2017; Reiss, 1991). This fact holds most true for the video 
observational method, which remains embryotic a decade on from its conception (Collins, 2008; Levine et al., 2011)—despite its privileged position to examine real-time violent interactions between multiple individuals. Given the emergent status of this method and its limited coverage in the study of violence (Lindegaard \& Copes, 2017; Nassauer \& Legewie, 2018), we will now provide recommendations for how to apply the video observational method for NTE violence research, while keeping the above methodological limitations in mind.

First, as aforementioned, there is a concern that the presence of CCTV cameras may alter the behaviors of those recorded. In our view, this issue should be acknowledged but not exaggerated. Just as crowdedness of the NTE settings should not be seen as something that 'disturbs' NTE behaviors, cameras are simply another natural component of the behavioral setting and therefore should not pose an ecological validity issue. In addition to this, the omnipresence of cameras in public spaces, and the 'normality' of being recorded, could mean that the behavioral reactivity to CCTV observation is low. This argument that people are habituated to camera surveillance is supported by findings that CCTV coverage is an ineffective deterrent for reducing emotionally reactive, public space violence (Alexandrie, 2017; Welsh \& Farrington, 2009).

Second, video data may suffer from a sampling bias, as it tends to be collected from severe police incidents or from social media sites broadcasting extraordinary cases (Lindegaard \& Bernasco, 2018). To circumvent this bias, researchers should aim to acquire a random probability sample covering both violently severe incidents and mundane nonphysical conflicts. Levine and colleagues (2011) adopted this latter approach by instructing CCTV operatives to record any incident that looked like it had the potential to become violent, whether police reported or not. Another solution could be to continually record a NTE zone over a set period of time. From this point, all conflicts, from the very mildest to the 
most severe, could be assessed. This most complete approach has been fruitfully applied in the criminal context of shoplifting offences (see Dabney, Hollinger, \& Dugan, 2004).

Third, CCTV data provides thin information on the social meaning, emotions, and motivational aspects of NTE violence, because sound and verbal information is typically unavailable. One way for scholars to minimize this issue is to draw upon the nonverbal communication literature, which demonstrates that a range of these socio-psychological properties can be perceived and deduced via non-verbal behavioral cues (Murphy, 2016). For example, some emotions (e.g., anger, pride) may be identified from postural and facial cues (de Gelder, 2009; Ekman \& Friesen, 1975; Tracy \& Matsumoto, 2008), and certain verbal expressions (aggressive utterances included) have nonverbal behavioral equivalents and that can be inferred without sound (Darwin, 1872; Eibl-Eibesfeldt, 1989). Furthermore, interactional displays of collective behavior-in-concert (e.g., bodily synchrony and proximity), can be used to ascertain social relationships between those observed (Afifi \& Johnson, 2005; Ge, Collins, \& Ruback, 2012; Goffman, 1971).

Although there is evidence that non-verbal communication can be employed to indirectly furnish additional social and verbal information, CCTV analyses would undoubtedly benefit from triangulation with other data sources. For example, Liebst and colleagues (2018) utilized police case files corresponding to their CCTV footage to validate the social relationship ties already coded from non-verbal communication cues. Alternatively, researchers could interview NTE patrons around CCTV covered areas once a conflict safely ends, thereby enriching the behavioral video data with self-reported accounts of experiences and meaning content. Further, persons of a NTE incident could be reunited with their footage in a restorative justice conference (Strang et al., 2013) to speak about their experiences, which could qualify the common understanding of the event (e.g., Bramsen, 2017). Such 
advances would address many of deficits inherent in CCTV data, but would also raise new ethical considerations.

Separate from the ethical issues arising from re-exposing the participants to the violent event experienced, there are also several ethical deliberations to consider when using CCTV footage - principally related to consent, anonymity, and confidentiality (see Kirkup \& Carrigan, 2000). As those observed are unable to provide consent, it is particularly important that any CCTV footage collected from public spaces has carefully considered and respected the privacy of the individuals captured. As such, camera data should only be sourced from demarcated public locations where those surveilled might expect to be observed by strangers. This complies with the Ethics Code of the American Psychological Association (2002), which states that researchers may dispense from obtaining informed consent in so far that "the research consists solely of naturalistic observations in public places, and it is not anticipated that the recording will be used in a manner that could cause personal identification or harm" $(\S 8.03)$.

To assure confidentiality and anonymity, it is imperative that all CCTV footage is safely stored on encrypted hard drives in a securely locked location. Handling of data should be carried out on computers without internet access. Data should not be shared across ordinary internet connections, hosting services, or via email. As the video footage (and any images pertaining to the footage) is for research purposes, these images should not be made available to unrelated third parties. Finally, any still frames used in academic work should have the faces of those people involved pixelated to protect their identities. In national contexts where no real image can be shown (even in a pixelated form), researchers are advised to present illustrative cases with written behavioral transcripts or anonymized drawn sketches (Bloch, Liebst, Poder, Christensen, \& Heinskou, 2018). 
In closing the paper, we recommend that the NTE violence field prioritizes triangulation of the outlined methods, thus compensating for the relative strengths and weaknesses inherent to each (Lingard, Albert, \& Levinson, 2008). A mixed-methods approach may be adopted within a specific research project, such as the protocol outlined by Miller and colleagues (2011), which combines patron and community surveys, informant interviews, on-site venue observations, and official records from the emergency services. Method mixing may also span across studies - an illustrative case of which is the recent advancement of the bystander research field. Traditionally, ideas on how bystanders behaved in public emergencies was assessed via the experimental method. Owing to questions of ecological validity, this method was supplemented by interviews asking people about their intervention experiences, and also with on-site observations of naturally occurring bystander behavior. More recently, researchers have started to assess the micro-interactional expression of NTE bystander behavior through CCTV data—as advocated by the current paper. Although the video approach sets a new benchmark for the analysis of fine-grained behavior during conflicts (Collins, 2008), the method lacks information regarding the meaning and motivations of the events. Lately, studies have compensated for this shortfall somewhat by triangulating video behavioral data with police case files that provide rich self-reported accounts.

This bystander subfield is just one example that illustrates how NTE research is methodologically maturing through the integration of complementary methods, both within and across studies. We believe that the NTE field is in a fortunate position of already having a rich array of methods, established and emerging alike, which supplement each other in a fruitful manner. As such, it is a case for increased awareness of these developments - for further evolution, rather than methodological revolution, of the NTE violence field. 


\section{References}

Adang, O. M. (2016). A method for direct systematic observation of collective violence and public order policing. Sociological Methods \& Research, 1-26.

Afifi, W. A., \& Johnson, M. L. (2005). The nature and function of tie-signs. In V. L. Manusov (Ed.), The sourcebook of nonverbal measures: Going beyond words (pp. 189-198). New Jersey: Psychology Press.

Alexandrie, G. (2017). Surveillance cameras and crime: a review of randomized and natural experiments. Journal of Scandinavian Studies in Criminology and Crime Prevention, $18(2), 210-222$.

Allen, J., Nicholas, S., Salisbury, H., \& Wood, M. (2003). Nature of burglary, vehicle and violent crime. In Crime in England and Wales 2001/2002 (Vol. Home Office Statistical Bulletin 01/03, pp. 41-68). London: Home Office.

Altmann, J. (1974). Observational study of behavior: Sampling methods. Behaviour, 49(3), 227-266.

Anderson, C. A., \& Bushman, B. J. (1997). External validity of "trivial" experiments: The case of laboratory aggression. Review of General Psychology, 1(1), 19-41.

Anderson, C. A., \& Bushman, B. J. (2002). Human aggression. Annual Review of Psychology, 53, 27-51.

Association, A. P. (2002). Ethical principles of psychologists and code of conduct. American Psychologist, 57(12), 1060-1073.

Ayres, T. C., \& Treadwell, J. (2012). Bars, drugs and football thugs: Alcohol, cocaine use and violence in the night time economy among English football firms. Criminology \& Criminal Justice, 12(1), 83-100.

Barnwell, S. S., Borders, A., \& Earleywine, M. (2006). Alcohol-aggression expectancies and dispositional aggression moderate the relationship between alcohol consumption and alcohol-related violence. Aggressive Behavior, 32(6), 517-527.

Baumeister, R. F., Ainsworth, S. E., \& Vohs, K. D. (2016). Are groups more or less than the sum of their members? The moderating role of individual identification. Behavioral and Brain Sciences, 39(e139), 1-56.

Baumeister, R. F., Vohs, K. D., \& Funder, D. C. (2007). Psychology as the science of selfreports and finger movements: Whatever happened to actual behavior? Perspectives on Psychological Science, 2(4), 396-403.

Bellis, M. A., Leckenby, N., Hughes, K., Luke, C., Wyke, S., \& Quigg, Z. (2012). Nighttime assaults: Using a national emergency department monitoring system to predict occurrence, target prevention and plan services. BMC Public Health, 12(746), 1-13.

Benson, D., \& Archer, J. (2002). An ethnographic study of sources of conflict between young men in the context of the night out. Psychology, Evolution \& Gender, 4(1), 3-30.

Berk, R. A. (1983). An introduction to sample selection bias in sociological data. American Sociological Review, 48(3), 386-398.

Bickman, L., \& Rog, D. J. (2008). The SAGE handbook of applied social research methods. London: Sage Publications Ltd.

Birdwhistell, R. L. 1970. Kinesics and context: Essays on body motion communication. Philadelphia: University of Pennsylvania Press.

Bloch, C., Liebst, L. S., Poder, P., Christensen, J., \& Heinskou, M. B. (2018). Caring collectives and other forms of bystander helping behavior in violent situations. Current Sociology. 0011392118776365. 
Block, R. L., Block, C. R. (1995). Space, place and crime: Hot spot areas and hot places of liquor-related crime. In J. E. Eck, \& D. Weisburd (Eds.) Crime and place, vol 5, Crime prevention studies (pp. 145-183). Monsey: Criminal Justice Press.

Bourdieu, P. (1999). The weight of the world: Social suffering in contemporary society. Stanford, CA: Stanford University Press.

Braga, A. A., Papachristos, A. V., \& Hureau, D. M. (2014). The effects of hot spots policing on crime: An updated systematic review and meta-analysis. Justice Quarterly, 31(4), 633-663.

Braga, A. A., \& Weisburd, D. (2010). Policing problem places: Crime hot spots and effective prevention. Oxford: Oxford University Press on Demand.

Bramsen, I. (2017). Route causes of conflict: Trajectories of violent and non-violent conflict intensification. (Doctoral dissertation), University of Copenhagen, Copenhagen.

Brennan, I. R. (2011). In vino silentium? Individual, situational, and alcohol-related factors in reporting violence to the police. Violence and Victims, 26(2), 191-207.

Burrell, A., \& Erol, R. (2009). Tackling violence in the night-time economy on the ground: Putting policy into practice in England and Wales. Crime Prevention and Community Safety, 11(3), 189-203.

Bushman, B. J., \& Cooper, H. M. (1990). Effects of alcohol on human aggression: An intergrative research review. Psychological Bulletin, 107(3), 341-354.

Caldwell, K., \& Atwal, A. (2005). Non-participant observation: Using video tapes to collect data in nursing research. Nurse Researcher, 13(2), 42-54.

Cialdini, R. B. (2009). We have to break up. Perspectives on Psychological Science, 4(1), 56.

Collins, R. (2008). Violence: A micro-sociological theory. Princeton: Princeton University Press.

Coomber, K., Pennay, A., Droste, N., Mayshak, R., Martino, F., Bowe, S. J., \& Miller, P. G. (2016). Observable characteristics associated with alcohol intoxication within licensed entertainment venues in Australia. International Journal of Drug Policy, 36, 8-14.

Copes, H., Hochstetler, A., \& Forsyth, C. J. (2013). Peaceful warriors: Codes for violence among adult male bar fighters. Criminology, 51(3), 761-794.

Crawford, A., \& Flint, J. (2009). Urban safety, anti-social behaviour and the night-time economy. Criminology and Criminal Justice, 9(4), 403-413.

Dabney, D. A., Hollinger, R. C., \& Dugan, L. (2004). Who actually steals? A study of covertly observed shoplifters. Justice Quarterly, 21(4), 693-728.

Dalgas, J. (2017, December 19 2017). Ny forskning: Det er ikke farligt at blande sig i slåskampe på gaden. Berlingske.

Darwin, C. (1872). The expression of the emotions in man and animals. London: John Murray.

de Andrade, D., Homel, R., \& Townsley, M. (2016). Trouble in paradise: The crime and health outcomes of the Surfers Paradise licensed venue lockout. Drug and Alcohol Review, 35(5), 564-572.

de Gelder, B. (2009). Why bodies? Twelve reasons for including bodily expressions in affective neuroscience. Philosophical Transactions of the Royal Society of London B: Biological Sciences, 364(1535), 3475-3484.

Diener, E. (1976). Effects of prior destructive behavior, anonymity, and group presence on deindividuation and aggression. Journal of Personality and Social Psychology, 33(5), 497-507.

Dyck, N. (1980). Booze, barrooms and scrapping: Masculinity and violence in a western Canadian town. Canadian Journal of Anthropology, 1(2), 191-198. 
Eibl-Eibesfeldt, I. (1989). Human ethology. New York: Aldine de Gruyter.

Ekman, P., \& Friesen, W. V. (1975). Unmasking the face: A guide to recognizing emotions from facial cues. Englewood Cliffs, NJ: Prentice Hall.

Elmes, D. G., Kantowitz, B. H., \& Roediger III, H. L. (2011). Research methods in psychology. Belmont, CA: Cengage Learning.

Farrington, D. P. (1998). Predictors, causes, and correlates of male youth violence. Crime and Justice, 24, 421-475.

Finkel, E. J. (2014). The $\mathrm{I}^{3}$ model: Metatheory, theory, and evidence. Advances in Experimental Social Psychology, 49, 1-104.

Finkel, E. J. \& Eckhardt, C. I. (2013). Intimate partner violence. In J. A. Simpson, \& L. Campbell (Eds.), The Oxford handbook of close relationships (pp. 452-474). New York: Oxford University Press.Fischer, P., Krueger, J. I., Greitemeyer, T., Vogrincic, C., Kastenmüller, A., Frey, D., . . Kainbacher, M. (2011). The bystander-effect: A meta-analytic review on bystander intervention in dangerous and non-dangerous emergencies. Psychological Bulletin, 137(4), 517-537.

Florence, C., Shepherd, J., Brennan, I., \& Simon, T. (2011). Effectiveness of anonymised information sharing and use in health service, police, and local government partnership for preventing violence related injury: Experimental study and time series analysis. British Medical Journal, 342, 1-9.

Forsyth, A. J., \& Lennox, J. (2010). Gender differences in the choreography of alcoholrelated violence: An observational study of aggression within licensed premises. Journal of Substance Use, 15(2), 75-88.

Frogner, L., Andershed, H., Lindberg, O., \& Johansson, M. (2013). Directed patrol for preventing city centre street violence in Sweden - a hot spot policing intervention. European Journal on Criminal Policy and Research, 19(4), 333-350.

Ge, W., Collins, R. T., \& Ruback, R. B. (2012). Vision-based analysis of small groups in pedestrian crowds. IEEE Transactions on Pattern Analysis and Machine Intelligence, 34(5), 1003-1016.

Geertz, C. (1973). Thick description: Toward an interpretive theory of culture. In C. Geertz (Ed), The interpretation of cultures: Selected essays (pp. 3-30). New York: Basic Books.

Geoffrion, S., Felson, M., Boivin, R., \& Ouellet, F. (2017). Systematic observation of barroom incidents in a large Montreal venue. Security Journal, 30(1), 123-141.

Gerell, M. (2016). Hot spot policing with actively monitored CCTV cameras: Does it reduce assaults in public places? International Criminal Justice Review, 26(2), 187-201.

Gerrard, G., \& Thompson, R. (2011). Two million cameras in the UK. CCTV Image, 42(10), 9-12.

Giancola, P. R. (2004). Executive functioning and alcohol-related aggression. Journal of Abnormal Psychology, 113(4), 541-555.

Giancola, P. R. (2013). Alcohol and aggression: Theories and mechanisms. In: M. McMurran (Ed.) Alcohol related violence: Prevention and treatment (pp. 37-59). Chichester: John Wiley \& Sons.

Gmel, G., Holmes, J., \& Studer, J. (2016). Are alcohol outlet densities strongly associated with alcohol-related outcomes? A critical review of recent evidence. Drug and Alcohol Review, 35(1), 40-54.

Goffman, E. (1971). Relations in public. Microstudies of the public order. New York: Basic Books.

Gorman, D. M., Speer, P. W., Gruenewald, P. J., \& Labouvie, E. W. (2001). Spatial dynamics of alcohol availability, neighborhood structure and violent crime. Journal of Studies on Alcohol, 62(5), 628-636. 
Graham, K., Bernards, S., Clapp, J. D., Dumas, T. M., Kelley-Baker, T., Miller, P. G., \& Wells, S. (2014). Street intercept method: An innovative approach to recruiting young adult high-risk drinkers. Drug and Alcohol Review, 33(4), 449-455.

Graham, K., \& Homel, R. (2012). Raising the bar. London: Routledge.

Graham, K., Osgood, D. W., Zibrowski, E., Purcell, J., Gliksman, L., Leonard, K., . . . Toomey, T. L. (2004). The effect of the Safer Bars programme on physical aggression in bars: Results of a randomized controlled trial. Drug and Alcohol Review, 23(1), 3141.

Graham, K., Tremblay, P. F., Wells, S., Pernanen, K., Purcell, J., \& Jelley, J. (2006). Harm, intent, and the nature of aggressive behavior: Measuring naturally occurring aggression in barroom settings. Assessment, 13(3), 280-296.

Graham, K., \& Wells, S. (2003). 'Somebody's gonna get their head kicked in tonight!'Aggression among young males in bars - a question of values?. British Journal of Criminology, 43(3), 546-566.

Gregoski, M., Malone, W. A., \& Richardson, D. S. (2005). Measuring direct and indirect aggression: Is there a response bias? Psychological Reports, 97(2), 563-566.

Groff, E. R., Weisburd, D., \& Yang, S.-M. (2010). Is it important to examine crime trends at a local "micro" level?: a longitudinal analysis of street to street variability in crime trajectories. Journal of Quantitative Criminology, 26(1), 7-32.

Hadfield, P., Lister, S., \& Traynor, P. (2009). 'This town's a different town today': Policing and regulating the night-time economy. Criminology \& Criminal Justice, 9(4), 465485.

Hammersley, M., \& Atkinson, P. (1995). Ethnography: Practices and principles. New York: Routledge.

Hedlund, J., Ahlner, J., Kristiansson, M., \& Sturup, J. (2014). A population-based study on toxicological findings in Swedish homicide victims and offenders from 2007 to 2009. Forensic Science International, 244, 25-29.

Hobbs, D., Hadfield, P., Lister, S., \& Winlow, S. (2005). Violence and control in the nighttime economy. European Journal of Crime Criminal Law and Criminal Justice, 13(1), 89-102.

Hobbs, D., O'Brien, K., \& Westmarland, L. (2007). Connecting the gendered door: Women, violence and doorwork. The British Journal of Sociology, 58(1), 21-38.

Hochstetler, A., Copes, H., \& Forsyth, C. J. (2014). The fight: Symbolic expression and validation of masculinity in working class tavern culture. American Journal of Criminal Justice, 39(3), 493-510.

Homel, R., \& Clark, J. (1994). The prediction and prevention of violence in pubs and clubs. Crime Prevention Studies, 3, 1-46.

Hughes, K., Anderson, Z., Morleo, M., \& Bellis, M. A. (2008). Alcohol, nightlife and violence: The relative contributions of drinking before and during nights out to negative health and criminal justice outcomes. Addiction, 103(1), 60-65.

Humphreys, D. K., \& Eisner, M. P. (2014). Do flexible alcohol trading hours reduce violence? A theory-based natural experiment in alcohol policy. Social Science \& Medicine, 102, 1-9.

Ito, T. A., Miller, N., \& Pollock, V. E. (1996). Alcohol and aggression: A meta-analysis on the moderating effects of inhibitory cues, triggering events, and self-focused attention. Psychological Bulletin, 120(1), 60-82.

Jackson-Jacobs, C. (2004). Taking a beating: The narrative gratifications of fighting as an underdog. In J. Ferrel, K. Hayward, W. Morrison, \& M. Presdee (Eds.), Cultural criminology unleashed (pp. 231-244). London: Glasshouse Press. 
Johnson, A., \& Sackett, R. (1998). Direct systematic observation of behavior. In H. R. Bernard (Ed.), Handbook of methods in cultural anthropology (pp. 301-332). Walnut Creek, CA: AltaMira Press.

Jorgensen, D. L. (1989). Participant observation: A methodology for human studies. Newbury Park, CA: Sage.

Kavanaugh, P. R. (2015). Pathways on the sexual violence continuum: A lifestyles theory of victimization in urban nightlife. Journal of Crime and Justice, 38(4), 454-472.

Kershaw, C., Nicholas, S., \& Walker, A. (2008). Crime in England and Wales 2007/08: Findings from the British Crime Survey. London: Home Office.

Kirkup, M., \& Carrigan, M. (2000). Video surveillance research in retailing: Ethical issues. International Journal of Retail \& Distribution Management, 28(11), 470-480.

Kypri, K. (2015). Commentary on de Gpeij et al. (2015): Evidence on harm from late night alcohol slaes continues to strengthen. Addiction, 110(6), 965-966.

Kypri, K. (2017). Commentary on Moore et al. (2017): Focus on policies rather than programmes to address alcohol-related violence. Addiction, 112(11), 1907-1908.

Kypri, K., McElduff, P., \& Miller, P. G. (2014). Restrictions in pub closing times and lockouts in Newcastle, Australia five years on. Drug and Alcohol Review, 33(3), 323326.

Kypri, K., Jones, C., McElduff, P., \& Barker, D. (2011). Effects of restricting pub closing times on night-time assaults in an Australian city. Addiction, 106(2), 303-310.

Laney, C., \& Takarangi, M. K. (2013). False memories for aggressive acts. Acta Psychologica, 143(2), 227-234.

Latané, B., \& Darley, J. M. (1970). The unresponsive bystander: Why doesn't he help? New York: Appleton-Century-Crofts.

LeCompte, M. D., \& Goetz, J. P. (1982). Problems of reliability and validity in ethnographic research. Review of Educational Research, 52(1), 31-60.

Lee, Y., Eck, J. E., O, S., \& Martinez, N. N. (2017). How concentrated is crime at places? A systematic review from 1970 to 2015. Crime Science, 6(6), 1-16.

Levine, M. (2003). Researching violence: Power, social relations and the virtues of the experimental method. In R. Lee \& E. Stanko (Eds.), Researching violence: Essays on methodology and measurement (pp. 126-136). London: Routledge.

Levine, M., Lowe, R., Best, R., \& Heim, D. (2012). 'We police it ourselves': Group processes in the escalation and regulation of violence in the night-time economy. European Journal of Social Psychology, 42(7), 924-932.

Levine, M., Taylor, P. J., \& Best, R. (2011). Third parties, violence, and conflict resolution: The role of group size and collective action in the microregulation of violence. Psychological Science, 22(3), 406-412.

Liebst, L. S., Heinskou, M. B., \& Ejbye-Ernst, P. (2018). On the actual risk of bystander intervention: A statistical study based on naturally occurring violent emergencies. Journal of Research in Crime and Delinquency, 55(1), 27-50.

Liebst, L. S., Philpot, R., Ejbye-Ernst, P., Dausel, K. L., Nicolaisen, M. H., Bernasco, W., . . . Lindegaard, M. R. (2018). Bystanders in Real-Life Dangerous Emergencies: Group Relationships Predict Intervention. Paper presented at the Danish Sociological Conference 2018, Esbjerg, Denmark.

Lindegaard, M. R., \& Bernasco, W. (2018). Lessons learned from crime caught on camera. Journal of Research in Crime and Delinquency, 55(1), 155-186.

Lindegaard, M. R., Bernasco, W., \& Jacques, S. (2015). Consequences of expected and observed victim resistance for offender violence during robbery events. Journal of Research in Crime and Delinquency, 52(1), 32-61. 
Lindegaard, M. R., \& Copes, H. (2017). Observational methods of offender decision making. In W. Bernasco, H. Elffers, \& J.-L. Van Gelder (Eds.), The Oxford handbook of offender decision making (pp. 498-521). Oxford: Oxford University Press.

Lingard, L., Albert, M., \& Levinson, W. (2008). Grounded theory, mixed methods, and action research. British Medical Journal, 337(a567), 459-461.

Lister, S. (2009). Police and policing. In A. Hucklesby \& A. Wahidin (Eds.), Criminal justice (pp. 37-58). Oxford: Oxford University Press.

Leonard, K., \& Senchak, M. (1993). Alcohol and premarital aggression among newlywed couples. Journal of Studies on Alcohol, 11, 96-108.

Macintyre, S., \& Homel, R. (1997). Danger on the dance floor: A study of interior design, crowding and aggression in nightclubs. In R. Homel (Ed.), Policing for prevention: Reducing crime, public intoxication and injury (pp. 91-113). Monsey, NY: Criminal Justice Press.

Martin, J. L. (2017). Thinking through methods: A social science primer. London: The University of Chicago Press.

Martín-Martín, A., Orduna-Malea, E., \& López-Cózar, E. D. (2018). Coverage of highlycited documents in Google Scholar, Web of Science, and Scopus: A multidisciplinary comparison. Preprint arXiv:1804.09479.

Maxfield, M. G., \& Babbie, E. R. (2014). Research methods for criminal justice and criminology. Belmont, CA: Cengage Learning.

Measham, F., \& Brain, K. (2005). 'Binge' drinking, British alcohol policy and the new culture of intoxication. Crime, Media, Culture, 1(3), 262-283.

Methven, E. (2014). A very expensive lesson: Counting the costs of penalty notice for antisocial behaviour. Current Issues in Criminal Justice, 26, 249-258.

Milgram, S. (1970). The experience of living in cities. Science, 167(3924), 1461-1468.

Miller, P. G., Bruno, R., Morgan, A., Mayshak, R., Cox, E., Coomber, K., Droste, N., Taylor, N., Dimitrovski, N., Peacock, A., Boxall, H., \& Voce, I. (2016a). Drug and alcohol intoxication and subsequent harm in night-time entertainment districts (DASHED):

Final report. Geelong, Australia: NDLERF. Available at: http://www.ndlerf.gov.au/publications/monographs/monograph-67.

Miller, P. G., Palmer, D., Droste, N., Tindall, J., Gillham, K., Sonderlund, A., McFarlane, E., de Groot, F., Sawyer, A., Groombridge, D., Lecathelinais, C., \& Wiggers, J. (2011). Dealing with alcohol-related problems in the night-time economy: A study protocol for mapping trends in harm and stakeholder views surrounding local community level interventions. BMC Research Notes, 4(204), 1-10.

Miller, P. G., Pennay, A., Jenkinson, R., Droste, N., Chikritzhs, T., Tomsen, S., Wadds, P., Jones, S. C., Palmer, D., Barrie, L., \& Lubman, D. I. (2013). Patron offending and intoxication in night time entertainment districts (POINTED): A study protocol. International Journal of Alcohol and Drug Research, 2(1), 69-76.

Miller, P. G., Tindall, J., Sønderlund, A., Groombridge, D., Lecathelinais, C., Gilham, K., McFarlane, E., de Groot, F., Droste, N., Sawyer, A., Palmer, D., Warren, I., \& Wiggers, J. (2012). Dealing with alcohol-related harm and the night-time economy (DANTE): Final report. Canberra, Australia: NDLERF. Available at: http://www.ndlerf.gov.au/publications/monographs/monograph-43.

Miller, P. G., Zinkiewicz, L., Hayley, A., Sonderlund, A., Litherland, S., Medew-Ewen, T., ... \& Graham, K. (2016b). Barroom aggression among Australian men: Associations with heavy episodic drinking, conformity to masculine norms, and personal and perceived peer approval of barroom aggression. Journal of Studies on Alcohol and Drugs, 77(3), 421-430. 
Monaghan, L. F. (2002). Hard men, shop boys and others: embodying competence in a masculinist occupation. The Sociological Review, 50(3), 334-355.

Moore, S. C., Fasihul Alam, M., Heikkinen, M., Hood, K., Huang, C., Moore, L., . . . Shovelton, C. (2017). The effectiveness of an intervention to reduce alcohol-related violence in premises licensed for the sale and on-site and consumption of alcohol: A randomised controlled trial. Addiction, 112(11), 1898-1906.

Moore, S. C., O’Brien, C., Alam, M. F., Cohen, D., Hood, K., Huang, C., . . . Sivarajasingam, V. (2014). All-Wales licensed premises intervention (AWLPI): A randomised controlled trial to reduce alcohol-related violence. BMC Public Health, 14(21), 1-10.

Morrison, C., Lee, J. P., Gruenewald, P. J., \& Mair, C. (2016). The reliability of naturalistic observations of social, physical and economic environments of bars. Addiction Research \& Theory, 24(4), 330-340.

Mortensen, C. R., \& Cialdini, R. B. (2010). Full-cycle social psychology for theory and application. Social and Personality Psychology Compass, 4(1), 53-63.

Murphy, N. A. (2016). What we know and the future of interpersonal accuracy research. In J. A. Hall, M. S. Mast, \& T. V. West (Eds.), The social psychology of perceiving others accurately (pp. 404-424). Cambridge: Cambridge University Press.

Nassauer, A., \& Legewie, N. M. (2018). Visual data analysis: A methodological frame for a novel research trend. Sociological Methods and Research. Online First.

Newton, A. (2015). Crime and the NTE: Multi-classification crime (MCC) hot spots in time and space. Crime Science, 4(1), 1-12.

Nicholls, E. (2017). 'Dulling it down a bit': Managing visibility, sexualities and risk in the night time economy in Newcastle, UK. Gender, Place \& Culture, 24(2), 260-273.

Parks, M. J., Osgood, D. W., Felson, R. B., Wells, S., \& Graham, K. (2013). Third party involvement in barroom conflicts. Aggressive Behavior, 39(4), 257-268.

Pedersen, A. -J. B., Kyvsgaard, B., \& Balvig, F. (2017). Udsathed for vold og andre former for kriminalitet. Offerunders $\phi$ gelserne 2005-2016. Copenhagen: Justitsministeriet, Københavns Universitet, Det Kriminalpræventive Råd, Rigspolitiet.

Perez-Trujillo, M., Reyes, M.-F., Cabrera, L., \& Gomez, A. P. (2016). Changing the beat: Fostering the prevention of alcohol-related violence in nighttime leisure zones. International Criminal Justice Review, 26(2), 169-186.

Phillips, B. S. (2001). Beyond sociology's tower of Babel: Reconstructing the scientific method. New York: Aldine.

Philpot, R. (2017). Beyond the dyad: The role of groups and third-parties in the trajectory of violence. (Doctoral dissertation), University of Exeter, Exeter.

Porter, T. (2015). Research on violence reduction. London: Cragg Ross Dawson.

Reiss, J. A. J. (1991). The trained incapacities of sociologists. In T. C. Halliday \& M. Janowitz (Eds.), Sociology and its publics (pp. 297-315). Chicago: University of Chicago Press.

Rossow, I., \& Norström, T. (2012). The impact of small changes in bar closing hours on violence. The Norwegian experience from 18 cities. Addiction, 107(3), 530-537.

Ritter, D., \& Eslea, M. (2005). Hot sauce, toy guns, and graffiti: A critical account of current laboratory aggression paradigms. Aggressive Behavior, 31(5), 407-419.

Sanchez-Ramirez, D. C., \& Voaklander, D. (2018). The impact of policies regulating alcohol trading hours and days on specific alcohol-related harms: A systematic review. Injury Prevention, 24, 94-100.

Saunders, D. G. (1991). Procedures for adjusting self-reports of violence for social desirability bias. Journal of Interpersonal Violence, 6(3), 336-344.

Schnitzer, S., Bellis, M. A., Anderson, Z., Hughes, K., Calafat, A., Juan, M., \& Kokkevi, A. (2010). Nightlife violence: A gender-specific view on risk factors for violence in 
nightlife settings: A cross-sectional study in nine European countries. Journal of Interpersonal Violence, 25(6), 1094-1112.

Schwartz, J., \& Vega, A. (2017). Sources of crime data. In B. Teasdale \& M. Bradley (Eds.), Preventing crime and violence. Advances in prevention science (pp. 155-167). Cham: Springer International Publishing.

Shepherd, J. (2007). Preventing alcohol-related violence: A public health approach. Criminal Behaviour and Mental Health, 17(4), 250-264.

Sherman, L. W., \& Weisburd, D. (1995). General deterrent effects of police patrol in crime "hot spots": A randomized, controlled trial. Justice Quarterly, 12(4), 625-648.

Simons, D. J., \& Chabris, C. F. (1999). Gorillas in our midst: Sustained inattentional blindness for dynamic events. Perception, 28(9), 1059-1074.

Slater, M., Rovira, A., Southern, R., Swapp, D., Zhang, J. J., Campbell, C., \& Levine, M. (2013). Bystander responses to a violent incident in an immersive virtual environment. PloS one, 8(1), e52766.

Stott, C., Hutchison, P., \& Drury, J. (2001). 'Hooligans' abroad? Inter-group dynamics, social identity and participation in collective 'disorder' at the 1998 World Cup Finals. British Journal of Social Psychology, 40(3), 359-384.

Stott, C., Scothern, M., \& Gorringe, H. (2013). Advances in liaison based public order policing in England: Human rights and negotiating the management of protest? Policing, 7(2), 212-226.

Strang, H., Sherman, L. W., Mayo-Wilson, E., Woods, D., Ariel, B., \& Strang, H. (2013). Restorative justice conferencing (RJC) using face-to-face meetings of offenders and victims: Effects on offender recidivism and victim satisfaction, a systematic review. Campbell Systematic Reviews, 9, 1-59.

Sykes, G. M., \& Matza, D. (1957). Techniques of neutralization: A theory of delinquency. American Sociological Review, 22, 664-670.

Taylor, S., \& Leonard, K. (1983). Alcohol and human physical aggression. In R. Geen, \& E. Donnerstein (Eds.), Aggression: Theoretical and empirical reviews (vol. 1) (pp. 77101). New York: Academic Press.

Tomsen, S. (1997). A top night: Social protest, masculinity and the culture of drinking violence. The British Journal of Criminology, 37(1), 90-102.

Townsley, M., \& Grimshaw, R. (2013). The consequences of queueing: Crowding, situational features and aggression in entertainment precincts. Crime Prevention and Community Safety, 15(1), 23-47.

Tracy, J. L., \& Matsumoto, D. (2008). The spontaneous expression of pride and shame: Evidence for biologically innate nonverbal displays. Proceedings of the National Academy of Sciences, 105(33), 11655-11660.

Tutenges, S., Søgaard, T. F., Krøll, L. T., Bloomfield, K., \& Hesse, M. (2015). Violent work environments: A survey of bouncers and their experiences of violence, stress and other work-related problems. International Journal of Workplace Health Management, 8(2), 129-141.

Uprichard, E., Burrows, R., \& Byrne, D. (2008). SPSS as an 'inscription device': From causality to description? The Sociological Review, 56(4), 606-622.

van Bommel, M., van Prooijen, J.-W., Elffers, H., \& van Lange, P. A. (2014). Intervene to be seen: The power of a camera in attenuating the bystander effect. Social Psychological and Personality Science, 5(4), 459-466.

van Gelder, J.-L., Otte, M., \& Luciano, E. C. (2014). Using virtual reality in criminological research. Crime Science, 3(10), 1-12.

van Kesteren, J., van Dijk, J., \& Mayhew, P. (2014). The international crime victims surveys: A retrospective. International Review of Victimology, 20(1), 49-69. 
Vrij, A., Hope, L., \& Fisher, R. P. (2014). Eliciting reliable information in investigative interviews. Policy Insights from the Behavioral and Brain Sciences, 1(1), 129-136.

Weenink, D. (2014). Frenzied attacks. A micro-sociological analysis of the emotional dynamics of extreme youth violence. The British Journal of Sociology, 65(3), 411433.

Weisburd, D. (2015). The law of crime concentration and the criminology of place. Criminology, 53(2), 133-157.

Wellington, J., \& Szczerbinski, M. (2007). Research methods for the social sciences. London: Continuum International Publishing Group.

Wells, S., Speechley, M., Koval, J. J., \& Graham, K. (2007). Gender differences in the relationship between heavy episodic drinking, social roles, and alcohol-related aggression in a US sample of late adolescent and young adult drinkers. The American Journal of Drug and Alcohol Abuse, 33(1), 21-29.

Welsh, B. C., \& Farrington, D. P. (2009). Public area CCTV and crime prevention: an updated systematic review and meta-analysis. Justice Quarterly, 26(4), 716-745.

Wilkinson, C., Livingston, M., \& Room, R. (2016). Impacts of changes to trading hours of liquor licences on alcohol-related harm: A systematic review 2005-2015. Public Health Research \& Practice, 26, e2641644.

Winlow, S., Hobbs, D., Lister, S., \& Hadfield, P. (2001). Get ready to duck. Bouncers and the realities of ethnographic research on violent groups. British Journal of Criminology, $41(3), 536-548$.

Wohlin, C. (2014). Guidelines for snowballing in systematic literature studies and a replication in software engineering. In 8th International Conference on Evaluation and Assessment in Software Engineering (EASE 2014), pp. 321-330.

Zimbardo, P. G. (2007). The Lucifer effect: Understanding how good people turn evil. New York: Random House. 